\title{
A note on languages
}

Current linguistic classification indicates that the people called the Yonggom and the Muyu speak three distinct languages: Northern Kati (or KatiNinati), Southern Kati (also Digoleesch or Kati-Metomka), and Yonggom or Yongkom (Foley 1986:239; see also Capell 1969:140-4I; Healey 1964; Silzer and Heikkinen 1984:75, 76, 82; and Voorhoeve 1980:26-27). However, this determination is based on limited data because the international border that divides the Yonggom and the Muyu has impeded comparative analysis. Close relationships between these language varieties have long been noted. During the first Australian colonial patrol to the North Fly, Leo Austen (1923:340) observed that "the tribes along the western bank [of the Ok Tedi River] and ... perhaps as far west as the Disul [Digul] River in Dutch New Guinea, all speak a similar language with dialectic variations." The linguist C. L. Voorhoeve (1975:383) noted that Alan Healey (1964:44), author of the first study of the Ok language family, "reported that there is a fair degree of mutual intelligibility between Yonggom and Northern Kati," and that he obtained "similar information ... regarding Yonggom and Southern Kati." Voorhoeve (1975:383) also suggested that Yonggom "may turn out to be a dialect" of either Northern or Southern Kati. Peter J. Silzer and Helja Heikkinen (1984:75) subsequently noted that Yonggom may be "an alternative name for Northern Kati."

The Yonggom recognize a single language (weng mimo) that is composed of socially recognized but mutually intelligible dialects. The Yonggom have considerable knowledge of sociolinguistic variation, which in the past was one of the few ways to mark identity beyond the lineage. An analysis of seven recognized language varieties found that the average percentage of 
cognates was 77\%, although in several cases this was as high as 92\% (Pfantz et al. I991:7.4). Even when vocabulary differences exist, the primary term in one dialect may be recognized as a synonym by the speakers of another dialect. On the basis of interview data about sociolinguistic variation, my impression is that these language varieties form a dialect chain that extends from the northwest to the southeast after colonial-era population movements are taken into consideration. Stephen A. Wurm (1982:138, ni) tentatively reached a similar conclusion in a footnote, suggesting, "Yonggom may connect with Northern and Southern Kati as a link in a dialect chain, which would make these three languages a single language."

Yonggom, Ningerum, and Iwur belong to the Lowland Ok language subfamily (Voorhoeve 1975:25-27). These languages, together with the Mountain Ok languages spoken in the Star Mountains to the north, comprise the Ok family, which is part of the Trans-New Guinea phylum of nonAustronesian languages (McElhanon and Voorhoeve I970:I0). Neighboring languages include Awin or Aekyom, spoken to the east, which belongs to the Awin-Pare family, and Kaeti and Wambon, spoken by the Mandobo to the west, which belong to the Awyu family (McElhanon and Voorhoeve I970:IO; see Figure 3.I). All of these language families belong to the Central and South New Guinea stock. The Marind languages spoken to the south, including Boazi, belong to the same phylum, but a separate stock (McElhanon and Voorhoeve I970:I0).

During fieldwork conducted over a period of two years, I regularly interacted with native speakers of several Yonggom dialects. Four other languages are also used in varying degrees by the Yonggom, a legacy of the region's complex colonial history: Hiri Motu (also known as Police Motu), the colonial trade language of Papua, the southeast quadrant of the island; Tok Pisin or Neo-Melanesian, the colonial lingua franca of New Guinea, the northeast quadrant of the island; Bahasa Indonesia, known to its speakers in West Papua by the Dutch colonial name Melayu or Bahasa Melayu; and English, which is an official language of Papua New Guinea and the language of educational instruction. ${ }^{\mathrm{I}}$ Yonggom is the primary language spoken in the villages and in most urban households, although it incorporates a significant number of loan words. These introduced terms provide historical clues to the circulation of ideas and things, including the Bahasa Indonesian 
names for steel tools (kapak and karang for axes and machetes), salt (karam, from garam), village (kampong), and forest (utan). Common Hiri Motu loan words include those indicating assistance (durua), custom or culture (kara), and medicine or chemicals (muramura). More recent English loan words include government, landowner, mine, pollution, and environment. Tok Pisin was not widely spoken by the Yonggom when I began fieldwork in 1986 , but is now rapidly replacing Hiri Motu.

No language materials for Yonggom were available at the outset of my research except for several short word lists and a statement on phonemes (Bartel 1959). However, most of the young adults were familiar with English from the local primary school, and several of them spoke the language with relative ease. I also used Hiri Motu vocabulary learned from books and tapes. Tok Pisin, which I studied before my first trip to Papua New Guinea, was of little use in the village. Although I acquired sufficient proficiency in Yonggom to work in the language, the following story suggests the limits of my abilities. In 1988, an expatriate missionary moved to a neighboring village with the intention of translating the Bible into Yonggom. During a visit to his house, he confessed his frustration with the slow pace of his language acquisition, and told me that his teachers attributed my knowledge of their language to magic used by people from the village where I lived. I was pleased by the backhanded compliment, until I related the anecdote to one of my research assistants, who laughed out loud at the claim-noting that their magic is far more efficacious!

Given the range of phonological variation across Yonggom dialects, my guidelines for spelling are simplicity and the conventions that the Yonggom themselves use when writing notes or letters in their own language. ${ }^{2}$ With the exception of proper nouns, Yonggom words are italicized, with long vowels transcribed as doubled. Yonggom nouns do not usually take a plural form, and consequently plurals are not indicated here. For more detailed information on Yonggom grammar, see Christensen (2000). ${ }^{3}$ For the other languages referenced in this text, my authorities are Mihalic (197I) for Tok Pisin, Dutton and Voorhoeve (1974) for Hiri Motu, and Echols and Shadily (1989) for Bahasa Indonesia. 

Reverse Anthropology 
